\title{
Translating monthly temperature from regional to local scale in the southeastern United States
}

\author{
Gregory J. Carbone *, Peter D. Bramante \\ Dept of Geography, University of South Carolina, Columbia, South Carolina 29208, USA
}

\begin{abstract}
This study investigates a statistically based scheme to translate climate information from the regional to local scale. Spatially averaged monthly maximum and minimum temperatures were used in a series of regression equations to predict similar variables at 62 stations across the southeastern United States. The spatial average temperature proved to be a good predictor of temperatures at most stations across the region. Model performance varied according to variable, season, and location. The highest model errors were associated with maximum temperature in summer, the lowest with minimum temperature in summer. While no general spatial patterns of errors were found, anomalously high errors appeared at individual stations. Since such anomalies often were associated with a variety of data discontinuities, the models provide a means of identifying whether individual stations are representative of the regional temperature time series. The regression models could also provide greater spatial resolution for climate impact scenarios as their error is usually far lower than the range of projected regional climate change produced by general circulation models.
\end{abstract}

KEY WORDS: Climate inversion - Statistical translation

\section{INTRODUCTION}

Researchers have explored several translation methods to derive local-scale climate information from actual or simulated regional-scale climate data (Wilks 1989, Giorgi 1990, Karl et al. 1990a, Wigley et al. 1990). The challenge is often referred to as the 'climate inversion' problem (Kim et al. 1984, Gates 1985), since climate is typically viewed as an aggregate of weather over time and space, and scaling down from a regional to local level involves data disaggregation. In climate impact research, such work is motivated by a need to make climate data more compatible with other model inputs, allowing analysis of the interaction between different physical processes at a coincident spatial scale (Clark 1985, Lamb 1987, Meentemeyer \& Box 1987, Cushman \& Farrell 1988, Meentemeyer 1989).

Statistically based approaches have been developed to translate regional-scale climate information to the local scale. Some are designed to identify the relation-

\footnotetext{
•E-mail: carbone@climate.geog.sc.edu
}

ship between GCM (general circulation model) output and the local observed climate. For example, Karl et al. (1990a) and Portman et al. (1992) developed statistical models to relate GCM free-atmosphere output to local observed climate variables. Similarly, von Storch et al. (1993) investigated the association between largescale pressure and circulation patterns and regionalscale observed winter rainfall. These studies exploited the ability of GCMs to reproduce such large-scale features reliably and of observations to characterize localscale conditions.

Other attempts have focused exclusively on the historic climate record and the relationship between areally averaged and individual station data. These efforts have addressed the translation issue through a series of statistical models, estimating the local-scale monthly or daily climate variables from predictor variables at a spatial scale that is comparable to a GCM grid cell (Kim et al. 1984, Wilks 1989, Wigley et al. 1990, Chen \& Robinson 1991). The implication of such methodology is that GCM output represents an average gridcell perturbation and that the historical relationship 
between regional- and local-scale climate variables would be maintained in the future. In most cases, statistical translation models have shown promising results, implying that the methodology could provide a starting point for more accurate climatic change scenarios at the local level. However, a need remains for further studies, using different data sets, to measure the accuracy of statistical translation schemes, and to evaluate the methodology within the context of climate change impact studies.

This paper focuses on statistical treatment of the translation issue and seeks (1) to determine the degree to which local-scale climate can be characterized by regional-scale climate in the southeastern United States (hereafter, Southeast); (2) to identify whether the accuracy of such characterization depends on season or location within the Southeast; and (3) to evaluate standards previously used to develop and assess statistical translation models. This effort provides a better understanding of the relationship between regional-scale and local-scale climatic variables in the Southeast, and provides an assessment of statistical translation methods generally.

Five hypotheses were tested. The first suggests that the spatially averaged monthly maximum and minimum temperature can serve as an accurate predictor of monthly temperature at individual stations within the Southeast. The second hypothesis is that the strength of the relationship between spatial average temperature and temperature at individual stations will vary by season. The third is that the strength of the relationship varies with location. Wigley et al. (1990) found that coastal and mountain influences and seasonal atmospheric patterns affecting the northwestern United States caused model accuracy to vary spatially and temporally. The fourth hypothesis argues that the time period used to calibrate and test regression models affects measures of their performance. Thus, regression models calibrated using data from consecutive years could perform differently from those using alternate years (e.g. even years). Finally, we believe that different measures of regression model accuracy will produce different results and, therefore, we examined differences between the coefficient of determination $\left(r^{2}\right)$ and mean absolute error to measure regression model performance.

\section{METHODS}

We address the translation question using an empirical model that measures the relationship between spatially averaged and local climatic variables. Mean monthly areally averaged maximum and minimum temperature were regressed against monthly mean minimum and maximum temperature at 62 stations within the southeastern United States. The study area consists of a grid cell that covers various physiographic regions (including the coastal plain, piedmont, and mountains) that characterize the region. It is a grid cell used in the National Center for Atmospheric Research (NCAR) Community Climate Model (CCM) with dimensions $31^{\circ} 05^{\prime}$ to $35^{\circ} 35^{\prime} \mathrm{N}$ latitude by $78^{\circ} 45^{\prime}$ to $86^{\circ} 15^{\prime}$ W longitude (Washington \& Meehl 1989). Temperature data come from the United States Historical Climatological Network (HCN), a network of 1219 station locations across the United States (Karl et al. 1990b). HCN data have been adjusted to estimate missing values, account for repositioned stations, instrument changes and changed observation times. The period 1901 to 1987 was chosen to maximize the number of stations with a long time series; all stations used have at least an 80 yr record.

The general linear regression model used to relate spatial average temperature to individual stations takes the form:

$$
\hat{T}_{i j k}=a_{i j}+b_{i j} \bar{T}_{\cdot j k}
$$

where $\hat{T}_{i j k}=$ maximum or minimum monthly temperature at station $i_{1}$ month $j$, year $k ; \bar{T}_{\cdot j k}=$ weighted spatial average maximum or minimum monthly temperature during month $j_{1}$ year $k_{i}$ and $a_{i j}$ and $b_{i j}$ are the intercept and regression coefficient, respectively.

We constructed Thiessen polygons around each of the 62 stations to compute weights accounting for variations in the distribution of stations within the grid cell (Fig. 1). Weighted spatial average maximum and minimum temperature, $\bar{T}_{\cdot j k}$, is computed as:

$$
\bar{T}_{\bullet \jmath k}=\frac{1}{n} \sum_{i=1}^{n} w_{i j} \cdot T_{\jmath j k}
$$

where $T_{i j k}=$ maximum or minimum monthly temperature at station $i$, month $j$, year $k ; w_{i j}=$ weight for station $i$, month $j$; and $n=$ number of stations in the grid cell.

Regression equations were developed for each month at the 62 stations for both maximum and minimum temperature. Two separate models were developed. Model I was calibrated with data from the latter half of the period (1945 to 1987) and validated against independent data from the early half of the period (1901 to 1944). Model II was calibrated using even years from 1901 to 1987 , and validated against odd years during the same time frame. Model I has the advantage of a consecutive temperature time series. However, because station moves or equipment changes are not perfectly accounted for in the $\mathrm{HCN}$ data preparation, Model I is sensitive to such changes that occur near the middle of the time series (1940 to 1950) where the data were split. Since Model II is cal- 
Fig. 1. Thiessen polygons for the 62 stations $(\bullet)$ in the $4.5^{\circ}$ latitude $\times 7.5^{\circ}$ longitude study region (southeastern U.S.). Numbers represent National Weather Service Index numbers

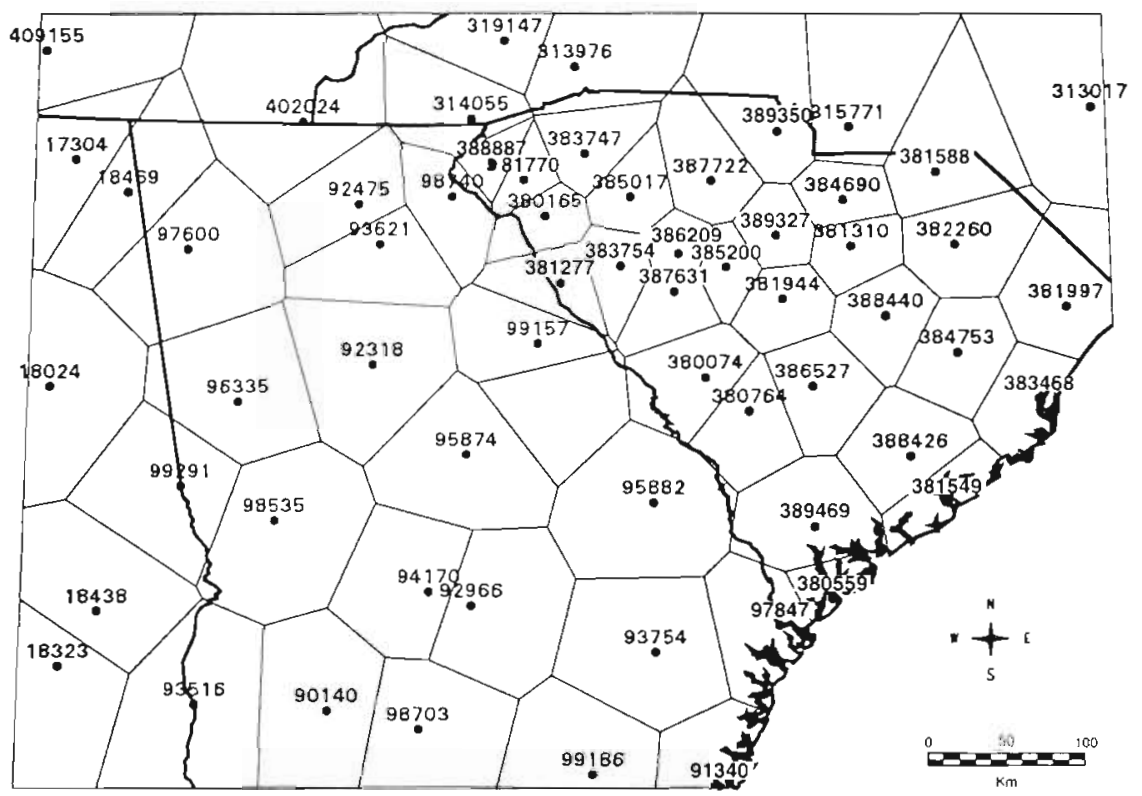

ibrated from data during the entire study period, it dampens the influence of such discontinuities or any climatic variation during the past century. Comparison of the 2 models should help to highlight errors resulting from data discontinuities at specific stations as Model I is likely to be more sensitive to such changes.

The regression models were evaluated using mean absolute error (MAE) and the coefficient of determination $\left(\mathrm{r}^{2}\right)$ to measure explained variance. Both measures are used here in order to determine whether evaluation of statistical translation techniques is sensitive to error measures. We used the latter measure because it is commonly used to evaluate model accuracy. However, others have suggested that $r^{2}$ values do not provide a consistent gauge of model performance (Fox 1981, Willmott 1982). MAE provides a good overall measure because it is not sensitive to extreme error values at individual stations and because it reports average error in the same units as the observed and predicted variables. This facilitates interpretation of regression model results with respect to climate impact studies.

The above methodology evaluates regression models over the historic temperature record. Since translation of climate information from the regional to the local scale is motivated by climate impact research, the errors resulting from translation schemes should be evaluated in this context. To this end, regression models were used with a regional climate change scenario for the Southeast to produce maximum and minimum temperature time series at individual stations. Output from NCAR's CCM provided monthly average re- gional temperature changes resulting from $\mathrm{CO}_{2}$ doubling. Exploiting the regression relationship derived from Model I above, monthly perturbed maximum and minimum temperature, $\hat{T}_{i j k}^{\prime}$, was calculated at individual stations as:

$$
\hat{T}_{i j k}=a_{i j}+b_{i j}\left(\bar{T}_{\cdot j k}+\Delta \bar{T}_{\mathrm{NCAR} \jmath}\right)
$$

where $a_{i j}=$ intercept derived from model calibration station $i_{1}$ month $j_{i} b_{i j}=$ regression coefficient derived from model calibration station $i$, month $j_{i} \bar{T}_{\cdot j k}=$ weighted spatial average grid cell temperature, month $j$, year $k_{i}$ and $\Delta \bar{T}_{\text {NCARj }}=$ GCM-derived grid cell temperature change for month $j$, averaged over a multiyear simulation.

The GCM output, combined with observed $\bar{T}_{\bullet, j k}$ values during the $44 \mathrm{yr}$ period 1901 to 1944 , provides a time series of potential temperature change at individual stations, assuming a fixed temperature perturbation without changes in interannual variability. The model further assumes that the relationship between regional average and individual station temperature, established from the empirical record, will be maintained under perturbed conditions.

\section{RESULTS AND DISCUSSION}

This section outlines seasonal and spatial patterns of model performance, compares the 2 regression models and the measures used to evaluate them, examines anomalies at individual stations, and evaluates the models in the context of local climate change scenarios. 


\section{Overall ability to estimate local-scale monthly temperature}

When considered generally, spatially averaged values reliably predict maximum and minimum temperatures at individual stations across the Southeast. The average coefficient of determination ranges between 51 and $93 \%$ (Table 1) and spatially averaged MAE ranges from 0.77 to $1.70^{\circ} \mathrm{C}$ (Table 2). A comparison across all stations and during validation years (independent data) shows that approximately $75 \%$ of all model estimates are within $\pm 1.25^{\circ} \mathrm{C}$ of those observed (Figs. $2 \& 3$ ). Underprediction at individual stations is offset by overprediction at others, such that modeled data from a range of stations could provide a realistic picture of regional conditions in an individual year. However, since we are hypothesizing that model errors vary with season, location, and test periods, closer examination is warranted if modeled data are to be used in climate impact studies.

Table 1 Monthly $\mathrm{r}^{2}$ values averaged over 62 stations across the southeastern U.S.

\begin{tabular}{|lcccc|}
\hline \multirow{2}{*}{ Month } & \multicolumn{2}{c}{ Model I } & \multicolumn{2}{c}{ Model II } \\
& Max. & Min. & Max. & Min. \\
\hline Jan & 0.90 & 0.92 & 0.90 & 0.93 \\
Feb & 0.90 & 0.89 & 0.88 & 0.88 \\
Mar & 0.90 & 0.90 & 0.90 & 0.89 \\
Apr & 0.78 & 0.74 & 0.83 & 0.76 \\
May & 0.74 & 0.76 & 0.74 & 0.77 \\
Jun & 0.68 & 0.69 & 0.70 & 0.71 \\
Jul & 0.62 & 0.61 & 0.60 & 0.59 \\
Aug & 0.53 & 0.57 & 0.62 & 0.51 \\
Sep & 0.83 & 0.82 & 0.82 & 0.79 \\
Oct & 0.73 & 0.85 & 0.78 & 0.89 \\
Nov & 0.82 & 0.80 & 0.82 & 0.85 \\
Dec & 0.88 & 0.89 & 0.89 & 0.88 \\
\hline
\end{tabular}

Table 2. Monthly mean absolute error $\left({ }^{\circ} \mathrm{C}\right)$ averaged over 62 stations across the southeastern U.S. Significant differences between maximum and minimum temperature for each model are noted at $99 \%\left({ }^{*}\right)$ and $95 \%\left({ }^{\circ}\right)$ confidence levels

\begin{tabular}{|c|c|c|c|c|}
\hline \multirow[t]{2}{*}{ Month } & \multicolumn{2}{|c|}{ Model I } & \multicolumn{2}{|c|}{ Model II } \\
\hline & Max. & Min. & Max. & Min. \\
\hline Jan & 1.38 & 1.32 & 1.14 & 1.11 \\
\hline Feb & 1.35 & 1.36 & 1.08 & 1.14 \\
\hline Mar & 1.36 & 1.36 & 1.05 & 1.09 \\
\hline Apr & 1.27 & 1.34 & 1.01 & 1.10 \\
\hline May & $1.44^{\circ}$ & 1.31 & 1.11 & 1.03 \\
\hline Jun & $1.70^{\circ}$ & 1.06 & $1.27^{\circ}$ & 0.88 \\
\hline Jul & $1.61^{\circ}$ & 1.00 & $1.16^{\circ}$ & 0.77 \\
\hline Aug & $1.46^{\circ}$ & 1.08 & $1.10^{\circ}$ & 0.86 \\
\hline Sep & $1.57^{\cdots}$ & 1.30 & $1.15^{\circ}$ & 1.02 \\
\hline Oct & 1.51 & 1.43 & 1.17 & 1.15 \\
\hline Nov & 1.49 & 1.44 & 1.12 & 1.19 \\
\hline Dec & 1.35 & 1.36 & 1.10 & 1.13 \\
\hline
\end{tabular}

\section{Seasonal variation}

As measured by $\mathrm{I}^{2}$ values, the models performed better during winter months than summer months (Fig. $4 \mathrm{a}-\mathrm{d}$ ). The coefficient of determination ranges from approximately $90 \%$ during winter months to $50 \%$ during summer months for both calibration and validation periods. The seasonal differences appear at nearly all stations and echo those found in previous studies (Wigley et al. 1990).

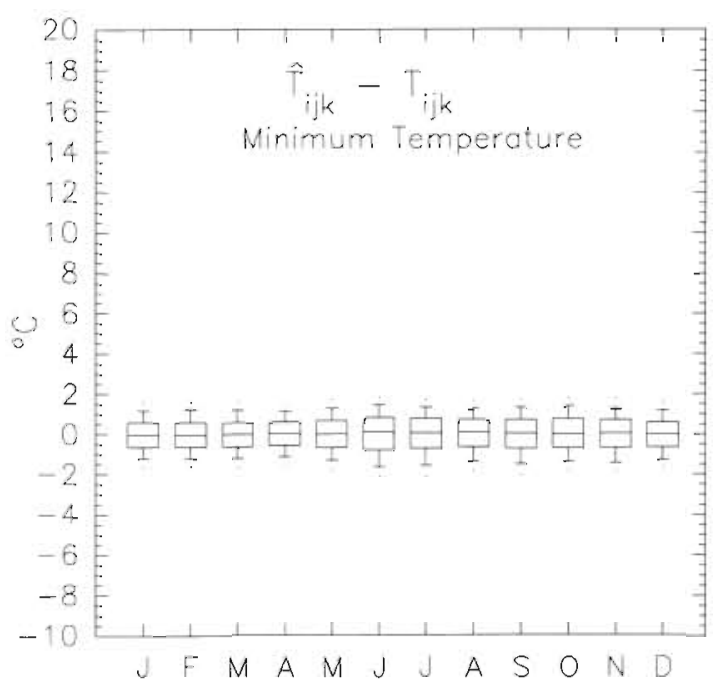

Fig. 2. Box plots showing frequency distribution of predicted minus Model I-observed monthly maximum temperature $\left(\hat{T}_{i j k}-T_{i j k}\right)$. The box represents a range from 25 th to 75 th percentiles, capped bars 10 th and 90 th percentiles, and dots 5 th and 95 th percentiles

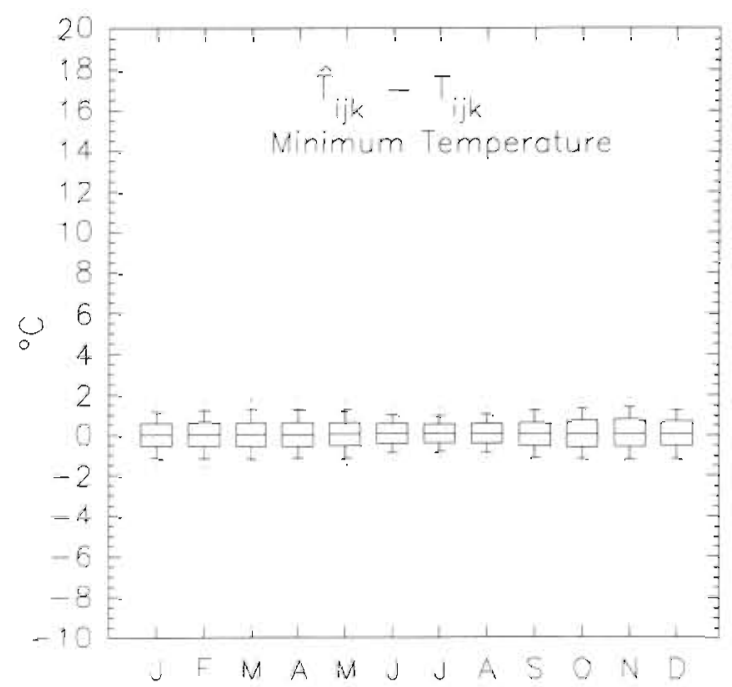

Fig. 3. Box plots showing frequency distribution of predicted minus Model I-observed monthly minimum temperature $\left(\hat{T}_{1 j k}-T_{1 j k}\right)$ 

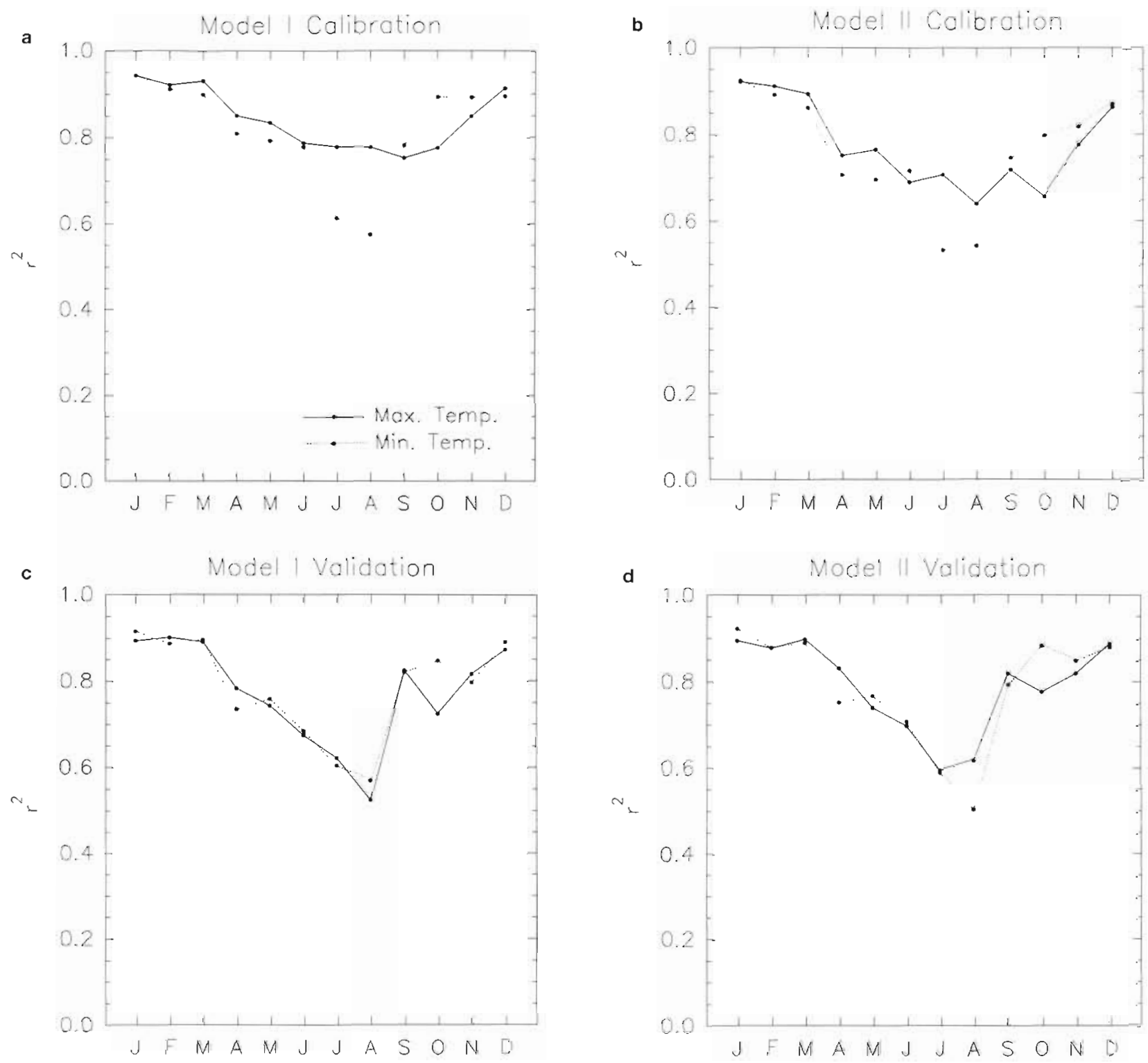

Fig. 4. Monthly $\mathrm{r}^{2}$ values for (a) Model I calibration period, (b) Model Il calibration period, (c) Model I validation period, (d) Model II validation period

MAE values, however, show different results. During model calibration there is relatively little seasonal variation in model fit. Maximum temperature errors from both models increase slightly during the summer months, while minimum temperature errors decrease slightly during the summer (Fig. 5a, b). These seasonal patterns are amplified somewhat when validated against an independent data set (Fig. 5c, d).

\section{Spatial variation}

The presence of spatial error patterns could indicate a systematic relationship between model perfor- mance and physiographic features. Such relationships have been identified in other regions using similar methodology (Kim et al. 1984, Wigley et al. 1990). These studies have identified areas where mesoscale processes, such as a sea breeze, can lead to poor model performance. They also have shown how certain features, such as mountain ranges, can improve predictability of local precipitation patterns. Figs. 6 to 9 show that no such subregional error patterns are present in the Southeast. Rather, anomalous errors are found at individual stations scattered throughout the study region. While the figures illustrate only January and July errors, the spatial patterns in these months are representative of those throughout the 
year. The lack of clear spatial patterns contrasts with previous results for the northwestern U.S. (Kim et al. 1984, Wigley et al. 1990). Unfortunately, the limited number of high elevation stations precludes a comprehensive comparison of model performance in these environments.

The lack of spatial error patterns along the coast is somewhat surprising. Despite differences in largescale circulation affecting the northwestern and southeastern U.S., both coastal regions do experience local sea breezes. Therefore, the poor model performance that Wigley et al. (1990) found in coastal environments of the former region would have been expected in the Southeast. Although there are isolated stations where error is particularly high (an issue discussed below), no clear spatial error patterns exist.

a

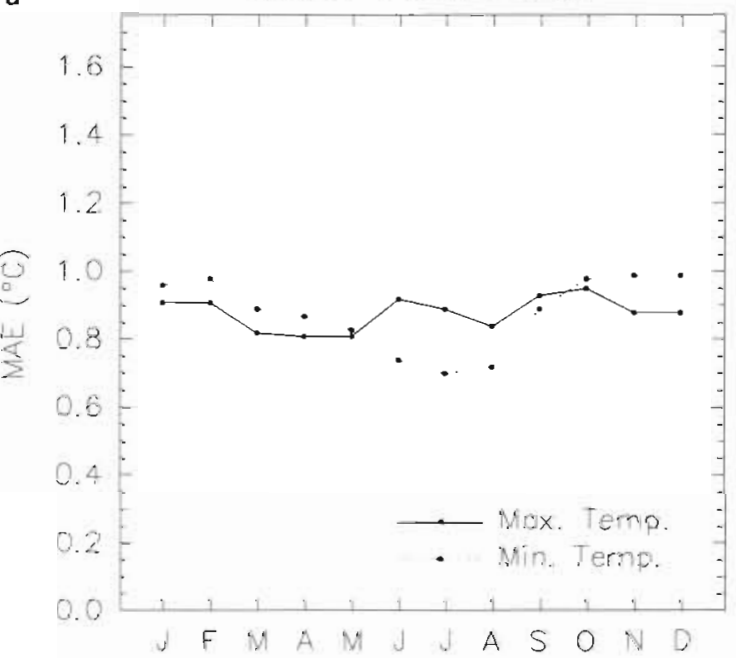

c

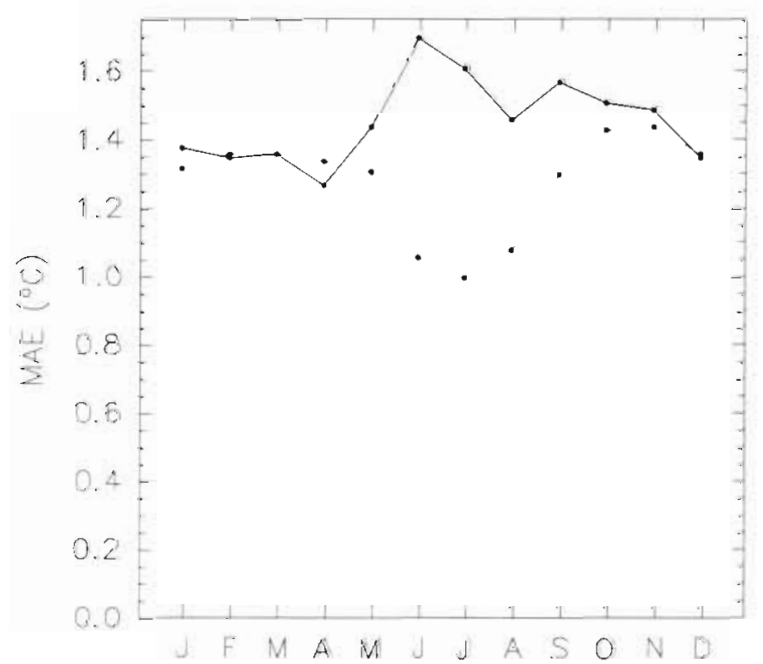

\section{Model differences}

Model I generally has a better fit than Model II during model calibration. An analysis of variance test shows that Model I produces significantly lower MAE of predicted maximum temperature during every month. MAE of predicted minimum temperature is also lower during every month using Model I; these differences are significant during January, March, April, and October. The differences in model performance relate to methods of data splitting. Model I is calibrated using consecutive years 1946 to 1987 . It has a better fit than Model II because there are fewer possibilities for discontinuities or climatic shifts that would affect the relationship between the spatial average temperature trend and individual stations.
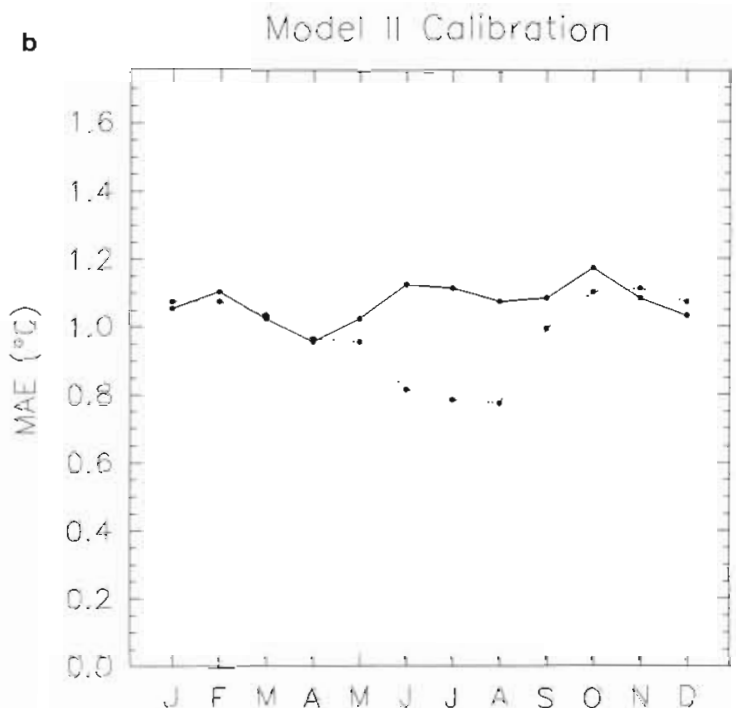

d

Model II Validation

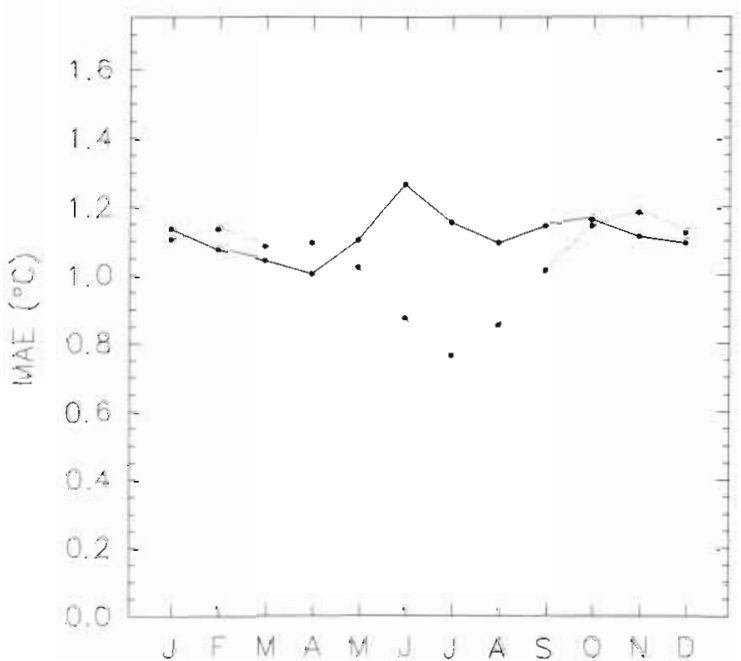

Fig. 5. Monthly mean absolute error (MAE) values for (a) Model I calibration period, (b) Model II calibration period, (c) Model I validation period, (d) Model II validation period 


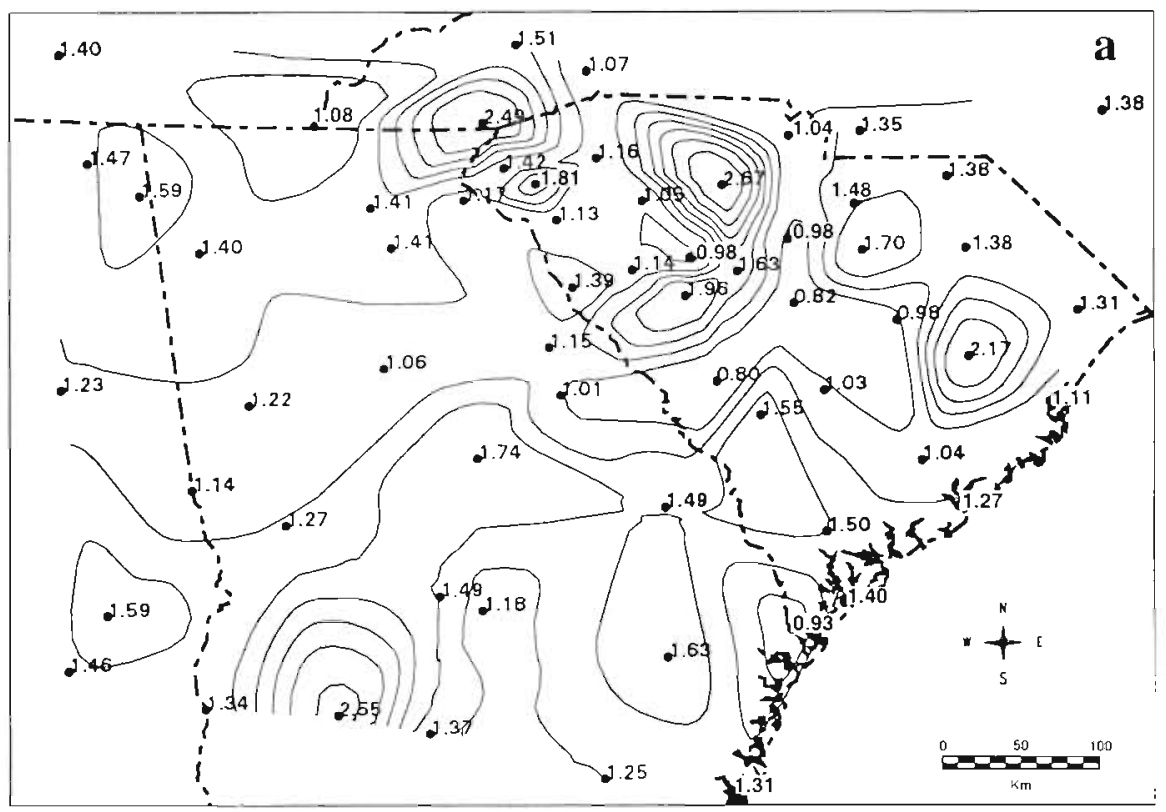

Fig. 6. Mean absolute error, January maximum temperature: (a) Model I. (b) Model Il. Contour interval is $0.25^{\circ} \mathrm{C}$

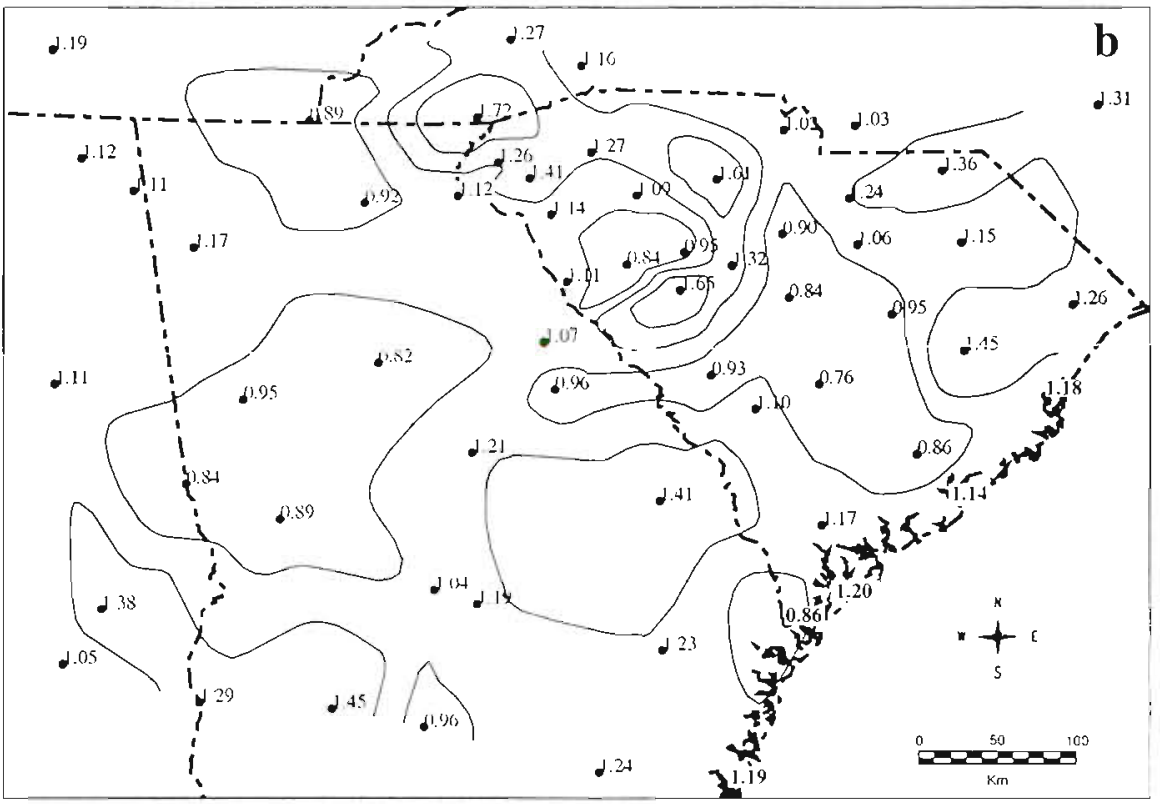

When validated against an independent data source, however, Model II outperforms Model I during every month for both maximum and minimum temperatures. While the regional average MAE is to some degree influenced by extreme values at a few individual stations, Model II outperforms Model I at most stations (Figs. 6 to 9). The differences again relate to methods of data splitting: Model I is sensitive to data discontinuities occurring close to the time that the data are split, 1944-45. Since Model II was constructed using data from the full time period, it accounts for both natural and anthropogenic temperature changes during the period and provides a more accurate prediction model.

\section{Measures of model performance}

Results from the 2 measures of model performance - the coefficient of determination $\left(\mathrm{r}^{2}\right)$ and MAE often conflict. The seasonal error patterns highlighted above provide a good example of the problem. Here $r^{2}$ values for minimum temperature were lower during the summer months, but MAE values indicated better model performance during the summer. It is likely that seasonal differences in $\mathrm{r}^{2}$ values could have a statistical rather than physical explanation. Low $\mathrm{r}^{2}$ values in summer probably result from relatively low interannual temperature variability during this season. Summers in 

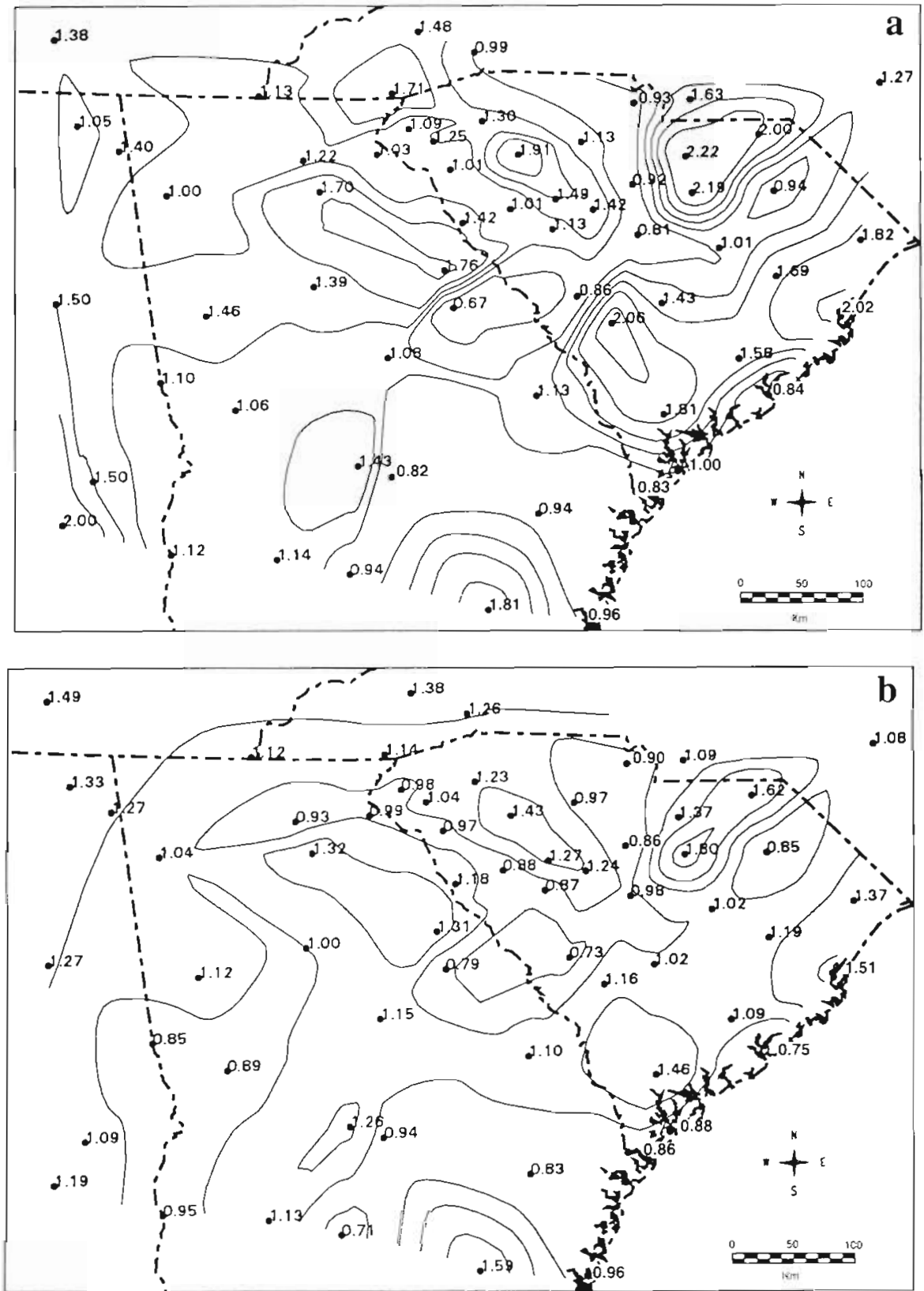

Fig. 7. Mean absolute error, January minimum temperature: (a) Model I. (b) Model II. Contour interval is $0.25^{\circ} \mathrm{C}$

the Southeast are consistently influenced by maritime tropical air masses and weak circulation, whereas winter circulation patterns, and consequently temperature, have much greater interannual variability.

Minimum temperature data from Blackville, South Carolina, provide an illustration of the discrepancies between the 2 error measures (Fig. 10). Here $\mathrm{r}^{2}$ values are lower during the summer months, indicating poorer model performance during this season. In July minimum predicted temperatures are relatively close to those observed, but there is relatively little interannual variability and little covariance between the predicted and observed temperature (Fig. 11). By contrast,
MAE values are lower during the summer, indicating better model performance. Interannual variability and covariance between predicted and observed values is higher in January, but the absolute difference between predicted and observed temperature is greater. This problem is consistent with results presented by Willmott (1982) and explains why $\mathrm{r}^{2}$ values may not present the best measure of model performance.

The sharpest discrepancy resulting from the use of different error measures is found with minimum temperature where $r^{2}$ values drop during summer months but MAE indicates better model performance. High water vapor content of maritime tropical air masses 


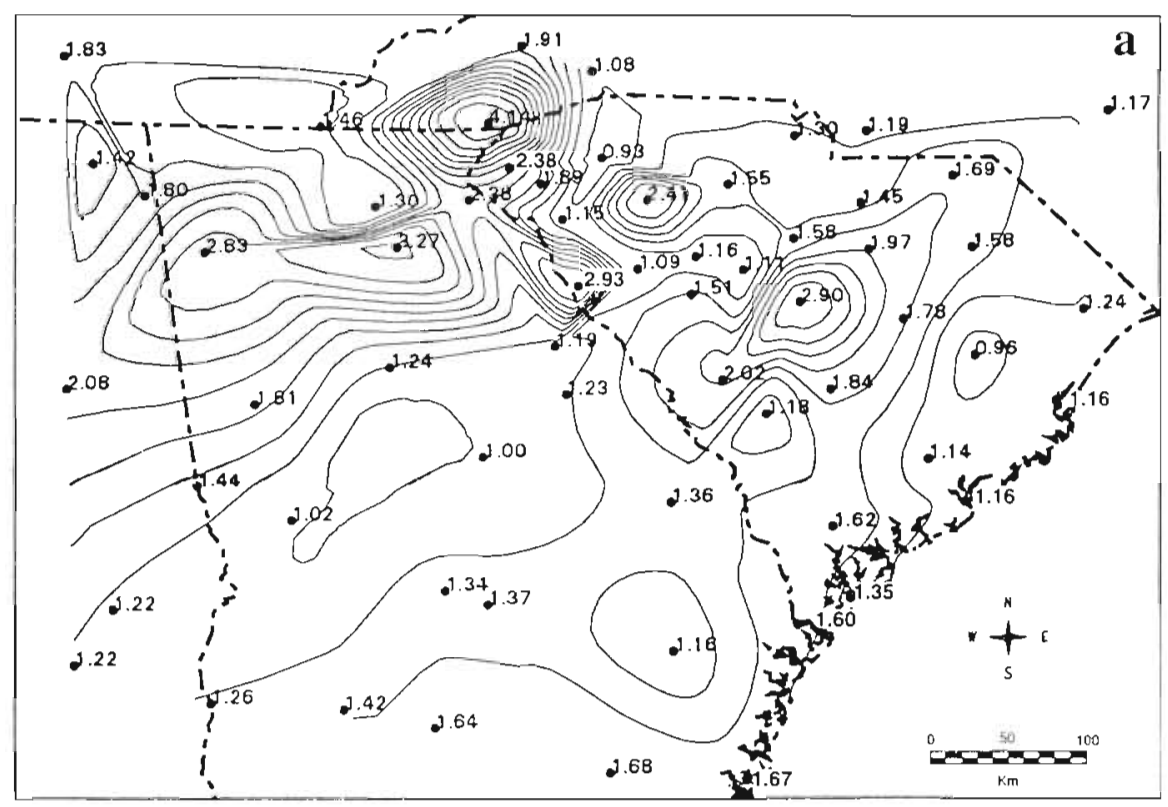

Fig. 8. Mean absolute error, July maximum temperature: (a) Model I, (b) Model Ir. Contour interval is $0.25^{\circ} \mathrm{C}$

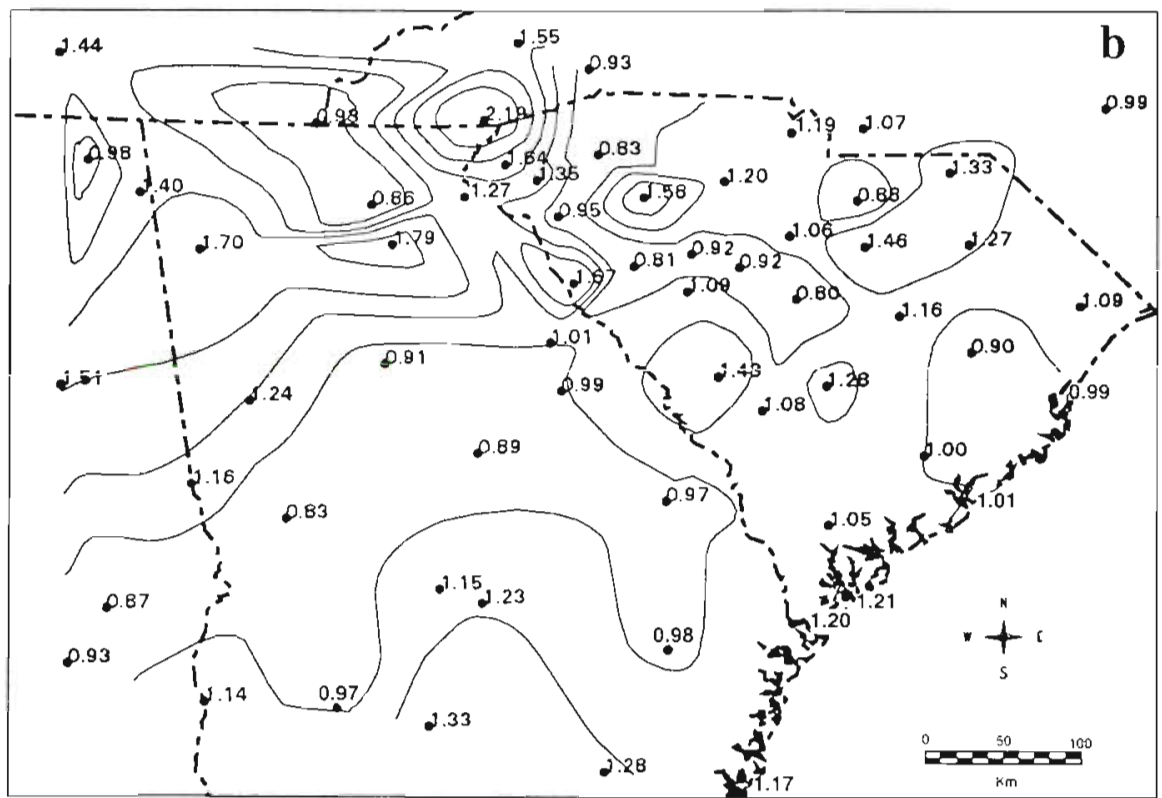

traps large amounts of long-wave radiation during the summer and keeps minimum temperatures within a narrow range. This lack of variability makes it difficult to capture covariance between regional and local temperature, but means that local temperature can be predicted fairly accurately in an absolute sense. Since variation in cloudiness can significantly influence interannual variability in maximum temperature, the contrast in accuracy is felt less dramatically with this variable. The differences between maximum and minimum temperature errors are expressed predominately during summer months when atmospheric water vapor content is highest. An analysis of variance test supports this idea as it shows that minimum temperature errors are significantly lower than maximum temperature errors during summer months, but that there are no significant differences during cooler months (Table 2).

\section{Anomalous errors}

Given that the data used in this study have been adjusted for a number of discontinuities, empirical translation models can serve as a secondary means of identifying stations with data discontinuities or stations not representative of the general region. Figs. 6 to 9 show that errors at individual stations are often anomalously high. Often such stations have been influenced by 

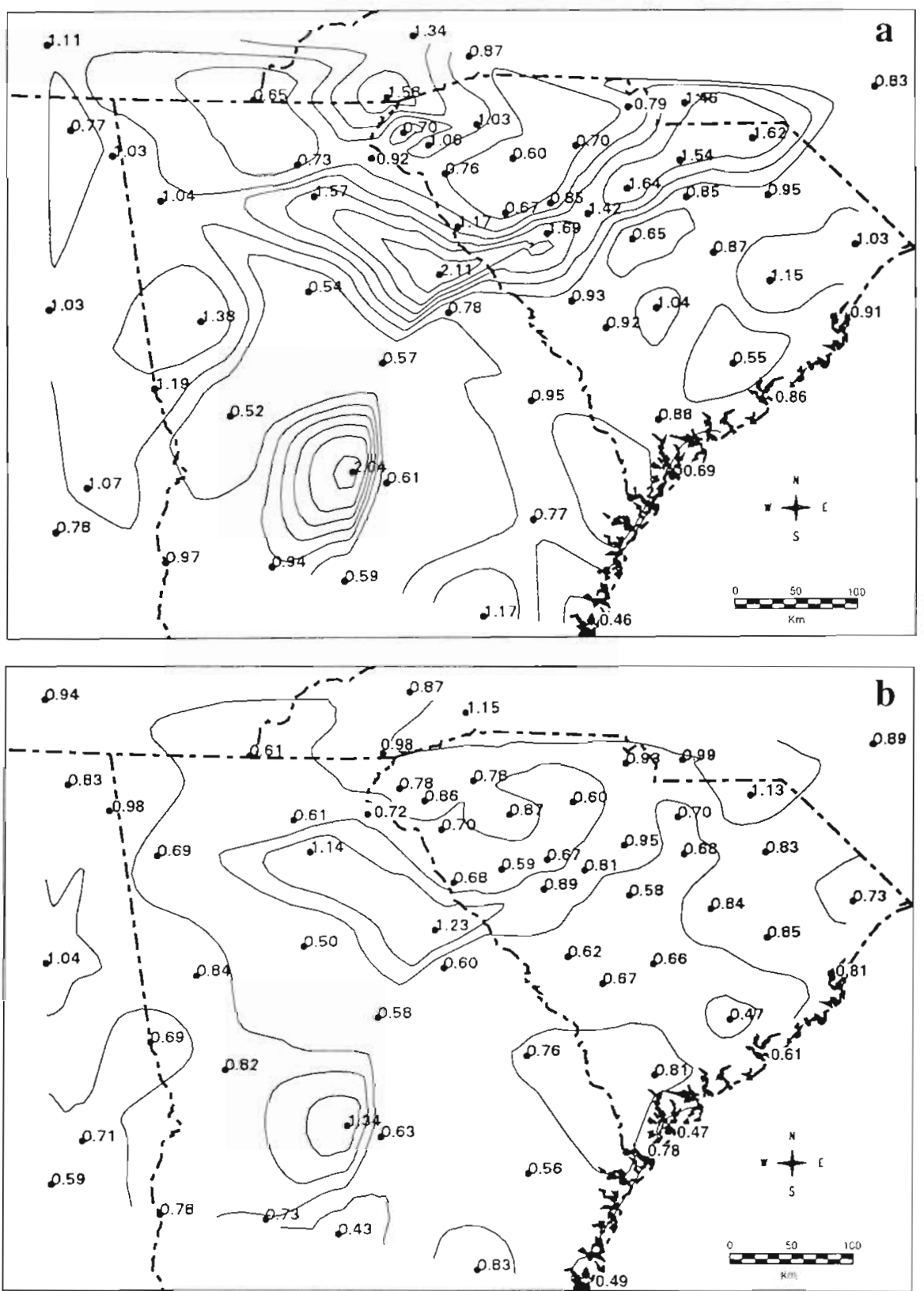

Fig. 9. Mean absolute error, July minimum temperature: (a) Model I, (b) Model II. Contour interval is $0.25^{\circ} \mathrm{C}$

changing observation time, station moves, urbanization, or other factors suddenly influencing the temperature record. While the HCN attempts to account for most of these discontinuities, its techniques are not perfect.

Four stations illustrate how statistical translation models can identify data inhomogeneities. The highest MAE for July minimum temperature is found at Washington, Georgia $\left(2.11^{\circ} \mathrm{C}\right.$; Fig. 9a). This station endured a number of station moves during the period of record. Perhaps more significant, however, was a change from afternoon to morning observations in 1957. Minimum temperature observations taken in the morning hours are occasionally carried over from the previous day. An examination of the predicted and observed minimum temperature time series for Washington shows that Model I underpredicts minimum temperature in the early part of the period (Fig. 12). This probably occurs because the model was calibrated during a period of morning temperature observations and tested against a period of afternoon temperature observations (when minimum temperatures are not typically carried over). A similar anomaly is found at Columbia, South Carolina, where July maximum MAE is $2.9^{\circ} \mathrm{C}$ (Fig 8a). Here the observation time was shifted from midnight to $17: 00 \mathrm{~h}$, a change that leads to greater frequency of maximum temperature carry-overs. Thus, Model I, cal- 

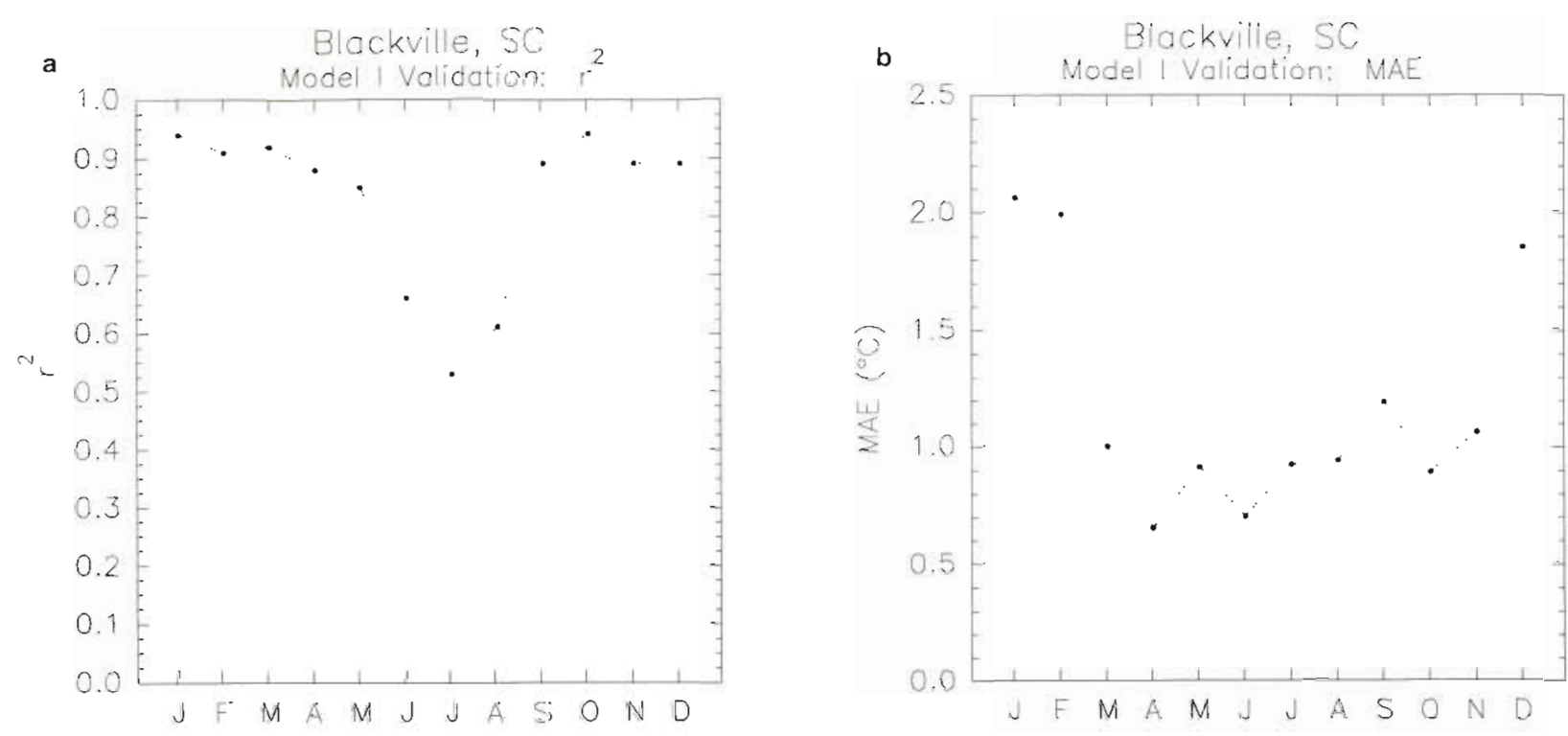

Fig. 10. Model l validation of monthly minimum temperature, Blackville, South Carolina: (a) $\mathrm{r}^{2}$; (b) mean absolute error (MAE)

ibrated from 1945-1987 data, overpredicts maximum temperature in the earlier part of the study period.

In other cases, site changes affect the temperature record and lead to anomalously high model errors. Calhoun Falls, South Carolina, near the Georgia border, has a relatively high MAE for July maximum temperature $\left(2.93^{\circ} \mathrm{C}_{i}\right.$ Fig. $\left.8 \mathrm{a}\right)$. While this station has had very few station moves, a dam built on the Savannah River in 1952 created a large lake that probably affected the local climate. The change affected model performance

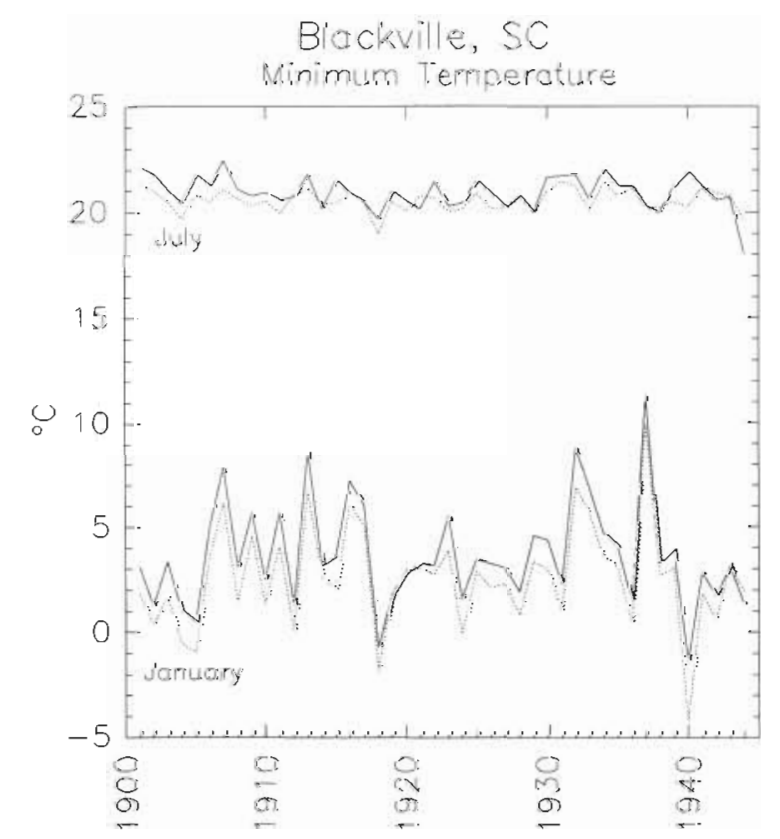

Fig. 11. Observed (solid line) and predicted (dotted line) minimum temperature time series for Blackville, South Carolina of summer maximum temperatures most significantly. Model I, calibrated with data from a cooler period after the dam was built, generally underpredicted July maximum temperatures in the early part of the century. A final example involves a station move at Camden, South Carolina. In 1950 this station in the north central part of the state was moved from a site at $222 \mathrm{ft}$ elevation (ca $68 \mathrm{~m}$ ) to a river valley at $170 \mathrm{ft}$ elevation (ca $52 \mathrm{~m}$ ). As a result of the station move, January minimum temperatures during the early part of the study period are consistently underpredicted and MAE is anomalously high (2.19 ${ }^{\circ} \mathrm{C}$; Fig. 7a).

\section{Magnitude and variability of local climate change scenarios}

Error associated with statistical translation schemes should be viewed with regard to climate change scenarios at the local scale (Table 3). To this end, Eq. (3) was used to produce a perturbed monthly maximum and minimum temperature time series over a $44 \mathrm{yr}$ period at each station in the grid cell. The time series at an individual station can be used to generate box plots illustrating the magnitude and variance of the projected perturbation for that station. The variance in projected temperature change at a station provides a measure of the range of likely scenarios, information that is particularly useful for climate impact studies.

Variance in the difference between a station's observed and projected temperature, $\operatorname{Var}\left(T_{\text {obs }}-T_{\text {proj }}\right)$, is defined by (Miller \& Wichern 1977):

$\operatorname{Var}\left(e_{i}-b_{1} \Delta T\right)=\operatorname{Var}\left(e_{i}\right)+\Delta T^{2} \operatorname{Var}\left(b_{1}\right)-2 \Delta T \operatorname{Cov}\left(e_{i} b_{1}\right)$ 
where $e_{1}=T_{i j k}-\left(a_{i j}+b_{1 j} \bar{T}_{\bullet k}\right) ; b_{1}$ is the regression coefficient, $b_{1 j}$; and $\Delta T$ is the GCM-projected regional temperature change.

Since $e_{i}$ and $b_{1}$ are uncorrelated, $\operatorname{Cov}\left(e_{i} b_{1}\right)=0$, and we have:

$$
\operatorname{Var}\left(e_{1}-b_{1} \Delta T\right)=\operatorname{Var}\left(e_{1}\right)+\Delta T^{2} \operatorname{Var}\left(b_{1}\right)
$$

Thus, variance in the temperature perturbation at an individual station depends on interannual variability in the observed temperature record and the magnitude of the projected regional temperature change. Projected maximum and minimum temperatures at Warrenton, Georgia, provide an illustration (Fig. 13). Variance of

Table 3. Projected temperature change $\left({ }^{\circ} \mathrm{C}\right)$ for a southeastern U.S. grid cell under conditions resulting from doubled $\mathrm{CO}_{2}$ in NCAR's Community Climate Model

\begin{tabular}{|ccc|}
\hline Month & \multicolumn{2}{c|}{$\begin{array}{c}\text { Change in: } \\
\end{array}$} \\
& Max. temp. & Min. temp. \\
\hline Jan & 2.94 & 3.17 \\
Feb & 3.28 & 4.66 \\
Mar & 4.84 & 6.38 \\
Apr & 3.00 & 3.14 \\
May & 3.56 & 3.13 \\
Jun & 3.55 & 3.30 \\
Jul & -0.79 & -0.01 \\
Aug & 2.59 & 2.53 \\
Sep & 1.30 & 1.78 \\
Oct & 4.18 & 4.14 \\
Nov & 2.86 & 3.53 \\
Dec & 4.89 & 5.45 \\
& & \\
\hline
\end{tabular}

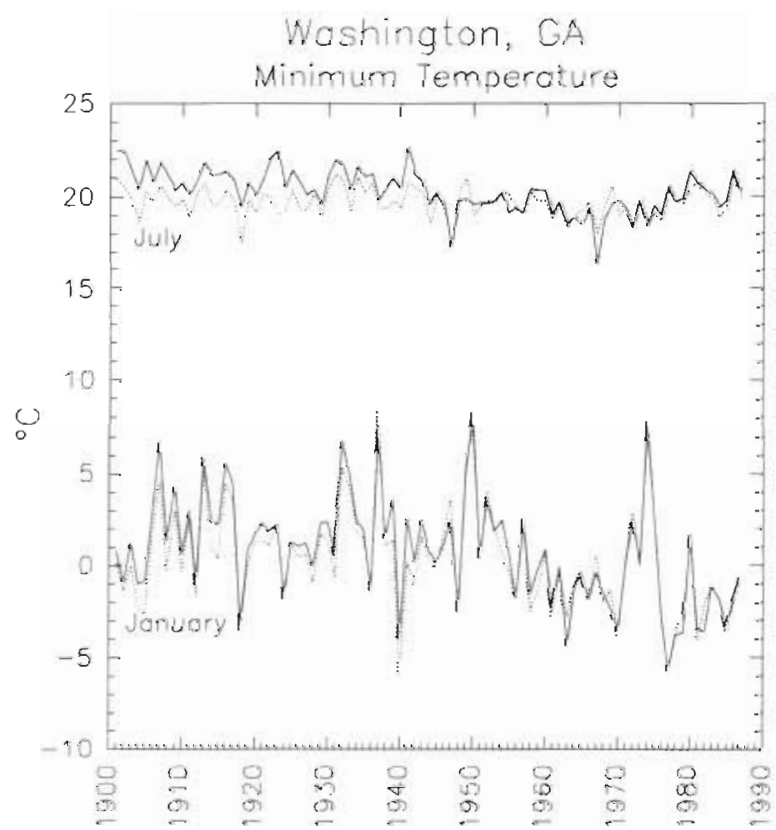

Fig. 12. Observed (solid line) and predicted (dotted linel minimum temperature time series for Washington, Georgia perturbed maximum and minimum temperature values at this station is relatively low during summer months when interannual temperature variability is small. Therefore, for a given projected temperature change, the range of values is generally smallest for minimum temperature during warmer months. (Compare, for example, difference in the variance between January and May.) Even under scenarios where $\Delta T$ is high during summer months (e.g. June), the range of values is relatively small. Variance is greatest during months that have high interannual temperature variability and relatively high projected temperature changes.

Box plots showing the variance associated with temperature perturbations at an individual station can be used to establish a range of values for climate impact
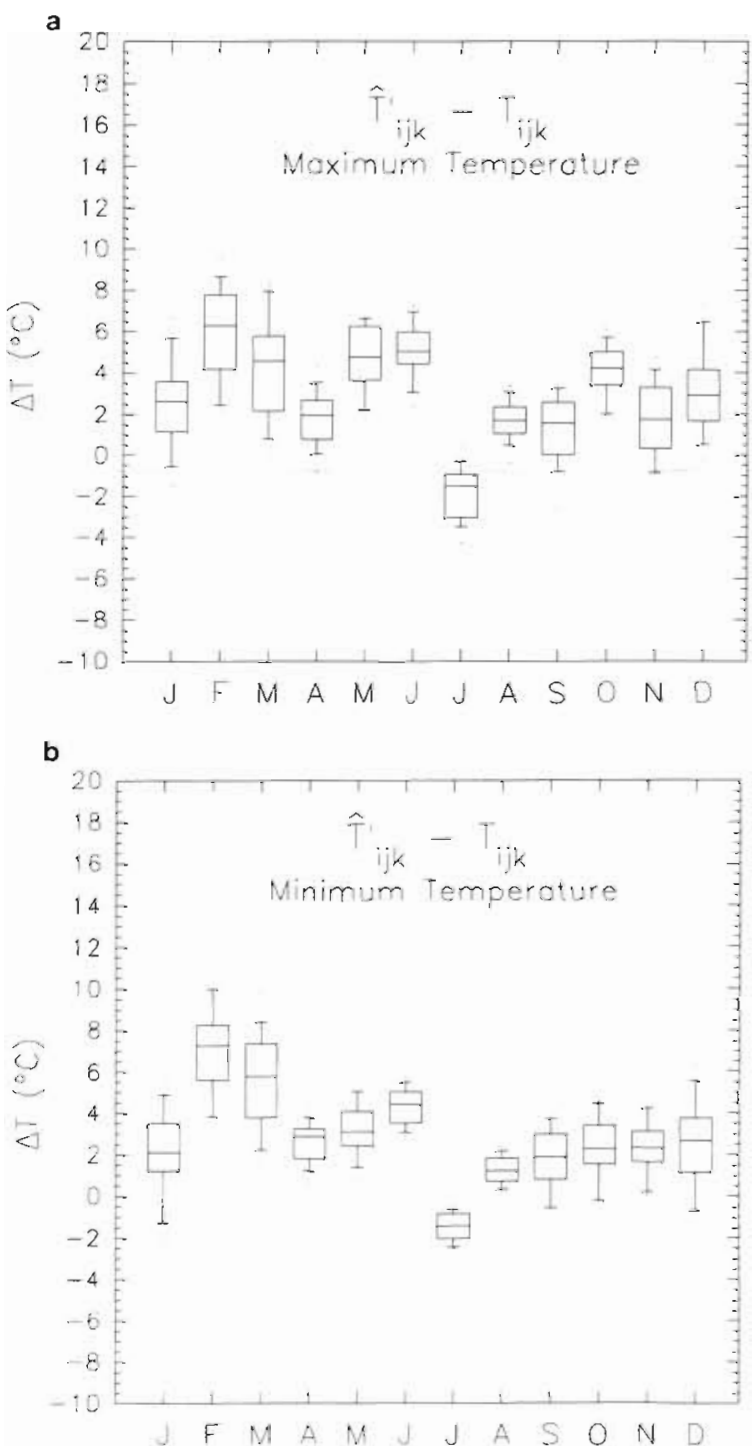

Fig. 1.3. Warrenton, Georgia, GCM-projected (a) maximum and (b) minimum temperature change over a 44 yr time series 
studies. This range could be incorporated into an impact model to provide a corresponding range of changes to a human or physical system. The distribution of values is, however, dependent on the accuracy of the prescribed regional temperature change from a general circulation model and on the assumption that no significant changes to current interannual variability will accompany such regional change.

\section{CONCLUSIONS}

Regression models estimate maximum and minimum temperature at stations in the Southeast with an accuracy on the order of $\pm 1.5^{\circ} \mathrm{C}$. Model accuracy varies with season. Errors in maximum temperature are slightly higher during summer months $\left(\mathrm{MAE} \approx 1.5^{\circ} \mathrm{C}\right.$ ), while errors in minimum temperature are generally lower during summer months $\left(<1.0^{\circ} \mathrm{C}\right)$. Low error values in summer minimum temperature are attributed to consistent warm, humid conditions and small interannual variability.

No clear spatial error patterns were found. While several anomalous stations had high error values, there were no consistent error patterns associated with physiographic subregions in the grid cell. In some cases, individual stations had high error values because of a station move or changing local environmental conditions, Regression models relating spatially averaged temperature to individual stations thus helped to identify stations that poorly reflect regional trends. Clearly, studies that include such stations could skew our view of regional climate impacts.

Error values also varied with the period used to construct the regression models. This study showed that a model calibrated to consider changes in a temperature series (Model II) performed better against an independent data set than one that did not (Model I). In the context of climate change studies, however, Model I provides a more realistic approach wherein a model is developed from a consecutive series of years and tested against a different time period. In either case, model robustness hinges on the assumption that past relationships between regional- and local-scale climatic variables can be extrapolated into the future.

Methods to evaluate statistically based translation models should also be more closely examined. This study found that $\mathrm{r}^{2}$ and MAE values can produce contrary results with respect to model performance. Errors associated with summer minimum temperature estimation provide evidence of how fairly accurate model projections that do not co-vary with observed values will result in low MAEs, but also low explained variance. In the context of climate impact research, though, models producing low absolute errors might be more useful than those simply capturing covariance between regional and local temperature.

The results of empirically based translation models can provide a range of values that must be considered in climate impact studies at the subregional scale. This range is a function of the magnitude and interannual variability of climate change scenarios and should be viewed with respect to the overall accuracy of the regression models themselves. Ultimately, of course, translation schemes used in conjunction with GCM results are constrained by the reliability of output at the grid-cell level. While GCMs can not presently provide reliable projections at this scale, the development of translation models used with output from several different models can provide a range of potential climate changes. Moreover, translation schemes may find utility with regional-scale climate change scenarios derived from other means such as analog methods

Physical approaches to the translation question have also been proposed. Nested modeling, for example, uses GCM output to drive a mesoscale atmospheric model simulating sub-grid-scale processes (Dickinson et al. 1989, Giorgi 1990, 1994). Some believe that this approach will enhance regional climate change scenarios while higher resolution GCMs are being developed (Mearns et al. 1992). Despite these efforts, statistical methods should continue to be used as they exploit the observed record with its detailed spatial and temporal resolution. In addition, regression models can measure how representative a particular station is of the region. In most cases, examples of high model error occur at stations that have experienced some form of data discontinuity. A statistical translation model offers an alternative method to identify such discontinuities and to initiate further analysis into the station history to understand their potential causes.

\section{LITERATURE CITED}

Chen RS, Robinson PJ (1991) Generating scenarios of local surface temperature using time series methods. J Clim 4: $723-732$

Clark WC (1985) Scales of climate impacts. Clim Change 7:5-27

Cushman RM, Farrell MP (1988) Climate and regional resource analysis: the effect of scale on resource homogeneity. Clim Change 12:129-148

Dickinson RE, Errico RM, Giorgi F, Bates GT (1989) A regional climate model for the western United States. Clim Change 15:383-422

Fox DG (1981) Judging air quality model performance: a summary of the AMS workshop on dispersion model performance. Bull Am Meteorol Soc 62:599-609

Gates W L (1985) The use of general circulation models in the analysis of the ecosystem impacts of climatic change. Clim Change $7: 267-284$

Giorgi $F(1990)$ Simulation of regional climate using a limited area model nested in a general circulation model. J Clim 3: 
$941-963$

Giorgi F (1994) Regional climate change scenarios over the United States produced with a nested regional climate model. J Clim 7:375-399

Karl TR, Wang WC, Schlesinger ME, Knight RW, Portman D (1990a) A method of relating general circulation model simulated climate to the observed local climate. Part I: Seasonal statistics. J Clim 3:1053-1079

Karl TR, Williams CN Jr, Quinlan FT (1990b) United States Historical Climatology Network ( $\mathrm{HCN}$ ) serial temperature and precipitation data. ORNL/CDIAC-30, NDP019/R1. Carbon Dioxide Information Analysis Center, Oak Ridge National Laboratory, Oak Ridge, TN

Kim JW, Chang JT, Baker NL, Wilks DS, Gates WL (1984) The statistical problem of climate inversion: determination of the relationship between local and large-scale climate. Mon Weath Rev 112:2069-2077

Lamb PJ (1987) On the development of regional climatic scenarios for policy-oriented climate-impact assessment. Bull Am Meteorol Soc 68:1116-1123

Mearns LO, Rosenzweig C, Goldberg R (1992) Effect of changes in interannual climatic variability on CERESwheat yields: sensitivity and $2 \times \mathrm{CO}_{2}$ general circulation model studies. Agri For Meteorol 62:159-189

Meentemeyer V (1989) Geographical perspectives of space,

Editor: V. Meentemeyer, Athens, Georgia, USA time, and scale. Landscape Ecol 3:163-173

Meentemeyer V, Box EO (1987) Scale effects in landscape studies. In: Turner MG (ed) Landscape heterogeneity and disturbance. Springer-Verlag, New York, p 15-34

Miller RB, Wichern DW (1977) Intermediate business statistics: analysis of variance, regression, and time series. Holt Rinehart and Winston, New York

Portman DA, Wang WC, Karl TR (1992) Comparison of general circulation model and observed regional climates: daily and seasonal variability. J Clim 5:343-353

von Storch H, Zorita E, Cubasch U (1993) Downscaling of global climate change estimates to regional scales: an application to Iberian rainfall in wintertime. J Clim 6:1161-1171

Washington WM, Meehl GA (1989) Climate sensitivity due to increased $\mathrm{CO}_{2}$ : experiments with a coupled atmosphere and ocean general circulation model. Clim Dyn 4:1-38

Wigley TML, Jones PD, Briffa KR, Smith G (1990) Obtaining sub-grid-scale information from coarse-resolution general circulation model output. J geophys Res 95(D2): $1943-1953$

Wilks DS (1989) Statistical specification of local surface weather elements from large-scale information. Theor appl Clim 40:119-134

Willmott CJ (1982) Some comments on the evaluation of model performance. Bull Am Meteorol Soc 63:1309-1313

Manuscript first received: January 28, 1995

Revised version accepted: April 4, 1995 